\title{
PERANCANGAN PEMBANGKIT TEGANGAN TINGGI IMPULS SEBAGAI OZONISASI DENGAN METODE KONVERTER FLYBACK
}

\author{
Azka Alfi Rijalul Fikri* ${ }^{*}$, Trias Andromeda dan Sudjadi \\ Departemen Teknik Elektro, Universitas Diponegoro \\ J1. Prof. Sudharto, SH, Kampus UNDIP Tembalang, Semarang 50275, Indonesia \\ ${ }^{*}$ E-mail: azkaalfi96@gmail.com
}

\begin{abstract}
Abstrak
Di era global ini, terdapat banyak sekali manfaat yang bisa diambil dari pemanfaatan ozon. Karena sifat oksidatornya yang sangat kuat, maka Ozon sangat unggul untuk desinfeksi (membunuh kuman), detoksifikasi (menetralkan zat beracun) dan deodorisasi (menghilangkan bau tidak enak) dalam air dan udara. Tidak sedikit dari pengaplikasian ozon dalam kehidupan sehari-hari, misalnya untuk peningkatan kualitas air, pengobatan ikan dalam akuarium, pengawetan makan bahkan untuk terapi penyembuhan luka bakar. Aplikasi tegangan tinggi dapat dimanfaatkan untuk pembentukan ozon. Umumnya tegangan tinggi dibangkitkan dengan menggunakan rangkaian konvensional berukuran besar. Untuk itu diperlukan rangkaian yang lebih sederhana untuk membangkitkan tegangan tinggi tersebut, misalnya dengan konverter flyback. Pada Penelitian ini, penulis merancang penerapan Zero Current Switching (ZCS) Pada Konverter Flyback untuk membangkitkan tegangan tinggi sebagai ozonisasi. Pada Penelitian ini dilakukan dua pengujian, yaitu pengujian tanpa beban variasi duty cycle dan pengujian jarak sela pada reaktor ozon. Pengujian dengan variasi duty cycle, nilai tegangan keluaran yang dihasilkan sebesar $11,01 \mathrm{kV}$ pada duty cycle $70 \%$. Pada pengujian jarak sela elektroda, konsentrasi yang tertinggi dihasilkan yaitu dengan tegangan terapan $7,47 \mathrm{kV}$ dan variasi jarak $5 \mathrm{~mm}$ yang menghasilkan $0,066 \mathrm{ppm}$.
\end{abstract}

Kata kunci : Konverter Flyback, Ozon

\begin{abstract}
This global era, there are many benefits that can be taken from the use of ozone. Because of its very strong oxidizing properties, Ozone is very superior for disinfection (killing germs), detoxification (neutralizing toxic substances) and deodorization (eliminating unpleasant odors) in water and air. Not a few from the application of ozone in everyday life, for example to improve water quality, treatment of fish in aquariums, preservation of food even for healing therapy for burns. High voltage applications can be used for ozone formation. Generally high voltages are generated by using large conventional circuits. For that required a simpler circuit to generate such high voltage, for example with a flyback converter. In this Final Project, the author designed the application of Zero Current Switching (ZCS) Flyback Converter is designed to generate high voltage for ozonation. In this Final Project, two tests are made. They are loadless testing duty cycle variation and intervals between the electrodes variations in ozone reactor. Duty cycle variation testing obtained the output voltage of $11,01 \mathrm{kV}$ at duty cycle of $70 \%$. Intervals between the elecrodes variation testing can produce ozone at ozone reactor which has been made with applied voltage $7,47 \mathrm{kV}$ and intervals between the electrode $5 \mathrm{~mm}$ with ozone concentration is $0,066 \mathrm{ppm}$.
\end{abstract}

Keywords: Flyback Converter, Ozone

\section{Pendahuluan}

Di era global ini, terdapat banyak sekali manfaat yang bisa diambil dari pemanfaatan ozon. Ozon sangat unggul untuk desinfeksi (membunuh kuman) detoksifikasi (menetralkan zat beracun) dan deodorisasi (menghilangkan bau tidak enak). Aplikasi tegangan tinggi dapat dimanfaatkan untuk pembentukan ozon. Pada umumnya tegangan tinggi dibangkitkan dengan mengunakan rangkaian konvensional berukuran besar[1][2]. Untuk itu diperlukan rangkaian yang lebih sederhana untuk membangkitkan tegangan tinggi tersebut, misalnya dengan konverter flyback. Penelitian pembangkitan tegangan tinggi dengan konverter flyback sudah cukup banyak dilakukan. Pada penelitian [3]-[7], dibahas mengenai pembangkitan tegangan tinggi Impuls menggunakan konverter flyback dengan didukung perangkat elektronika daya. Penelitian mengenai aplikasi tegangan tinggi untuk pembangkitan ozon juga sudah 
banyak dilakukan diantaranya penjernihan air dan pengolahan air limbah [7]-[9]. Metode pensaklaran dengan zero current switching pernah dilakukan pada penelitian [10] yang diterapkan pada konverter tipe buck.

Berangkat dari beberapa penelitian tersebut pada penelitian ini, penulis merancang penerapan Zero Current Switching (ZCS) pada konverter flyback untuk pembangkitan reaktor ozon sebagai ozonisasi. Zero Current Switching (ZCS) merupakan salah satu teknik soft-switching di mana MOSFET akan turn off atau turn on ketika arusnya bernilai nol. Teknik switching ini menggunakan kapasitor resonan (Cr) yang dipasang paralel dengan MOSFET dan induktor resonan (Lr) yang dipasang seri dengan kombinasi paralel dari MOSFET dan kapasitor resonan [11].

Tegangan keluaran hasil pembangkitan ZCS konverter flyback diterapkan pada reaktor untuk dihasilkan gas ozon atau sebagai ozonisasi. Reaktor ozon berupa elektroda jarum dan elektroda bidang dengan jarak sela antarelektroda bervariasi dari $1-9$ milimeter dengan variasi per jarak 2 milimeter.

\section{Metode}

Metode penelitian ini terdiri dari blok rangkaian penyearah, blok konverter flyback, dan blok reaktor ozon seperti yang ditunjukkan Gambar 1.

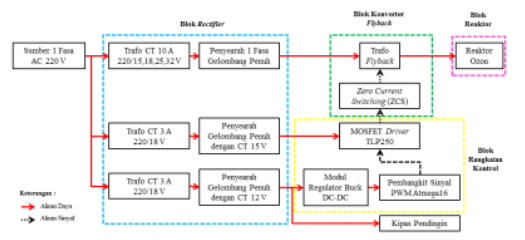

Gambar 1. Blok Diagram Alat

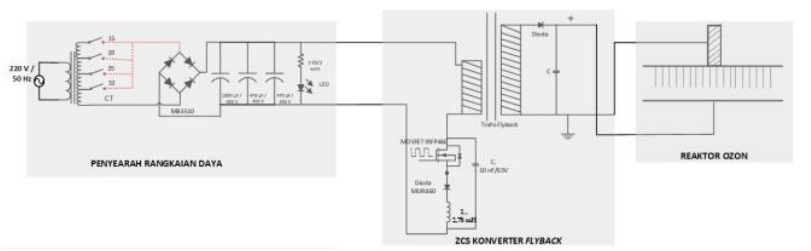

Gambar 2. Rangkaian ZCS Konverter Flyback

\subsection{Zero Current Switching (ZCS) Konverter Flyback}

Gambar 2 merupakan rangkaian ZCS konverter flyback sebagai ozonisasi. Rangkaian ZCS Konverter Flyback pada Penelitian ini tersusun dari komponen-komponen berikut:

1. Sumber Tegangan DC $\left(V_{i n}\right)$

Sumber tegangan yang digunakan sebagai suplai daya konverter berasal dari keluaran rangkaian penyarah 1 fasa gelombang penuh tak terkontrol.

2. Saklar

Komponen pensaklaran yang digunakan pada konverter tersebut adalah MOSFET. MOSFET yang digunakan adalah IRFP460 yang mampu menahan tegangan hingga $500 \mathrm{~V}[12]$.

3. Trafo

Trafo yang digunakan pada Penelitian ini adalah trafo flyback. Trafo flyback yang digunakan pada Penelitian ini berasal dari monitor CRT dengan inti ferrit. Tipe trafo yang digunakan adalah Trafo Flyback CRT BSC250-T1010A dengan nilai arus nominal 4A[13].

4. Dioda MUR 460

Komponen dioda yang digunakan pada Penelitian ini adalah dioda MUR460. Dioda ini dipilih karena dapat menghantar arus sebesar $4 \mathrm{~A}$ dan menahan reverse voltage hingga $600 \mathrm{~V}[14]$.

5. Induktor Resonansi $\left(\mathrm{L}_{\mathrm{r}}\right)$ dan Kapasitor Resonansi $\left(\mathrm{C}_{\mathrm{r}}\right)$ Nilai kapasitor dan induktor yang digunakan pada rancangan ZCS konverter flyback ini adalah kapasitor jenis MKM $10 \mathrm{nF} / 63 \mathrm{~V}$ dan induktor dengan nilai 2,78 $\mathrm{mH}$. Nilai induktor $\mathrm{L}_{\mathrm{r}}$ didapatkan dari Persamaan 2.

$$
\begin{aligned}
& f_{o}=\frac{1}{2 \pi \sqrt{L_{r} C_{r}}} \\
& L_{r}=\frac{1}{\left(2 \pi f_{o}\right)^{2} C_{r}}
\end{aligned}
$$

$$
\begin{aligned}
\text { Dimana : } & \\
\mathrm{f}_{\mathrm{o}} & : \text { Frekuensi resonansi } \\
\mathrm{C}_{\mathrm{r}} & : \text { Kapasitor resonan } \\
\mathrm{L}_{\mathrm{r}} & : \text { Induktor resonan }
\end{aligned}
$$

\subsection{Reaktor Ozon}

Pada penelitian ini, digunakan reaktor ozon dengan elektroda bentuk jarum bidang. Gambar 3 merupakan chamber elektroda yang digunakan pada Penelitian ini. Elektroda memiliki dimensi 16 x 11 x 5 cm dan mempunyai suatu mekanik untuk mengubah jarak elektroda yaitu menggunakan mur dan baut dengan rasio 1 putar adalah berjarak 2 milimeter.

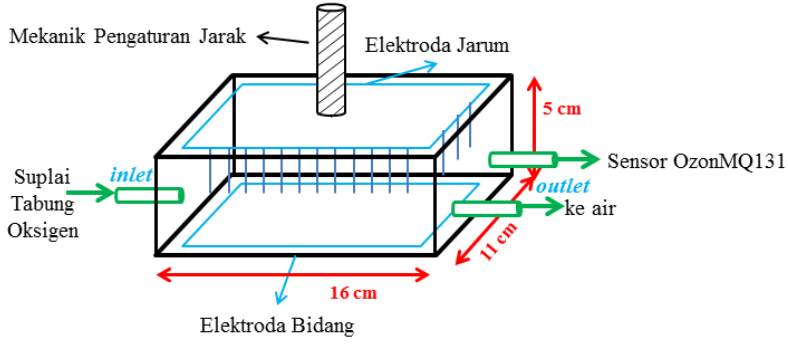

Gambar 3. Skema Elektroda Jarum-Bidang

Elektroda jarum terbuat dari bahan stainless steel dengan panjang $1 \mathrm{~cm}$ dan jarak antar jarum sebesar $1 \mathrm{~cm}$ dan elektroda plat terbuat dari bahan tembaga (PCB). Jarak bisa divariasikan agar bisa mengetahui pengaruh jarak pada elektroda jarum dan plat. Pemilihan elektroda jarum sebagai ground agar lebih sulit terjadi discharge antar elektroda saat tegangan dinaikkan sehingga medan listrik 
semakin besar. Semakin besar medan listrik di antara kedua elektroda, maka semakin banyak ozon yang terbentuk.

\section{Hasil dan Analisis}

\subsection{Pengujian Mode Pensaklaran Zero Current Switching (ZCS) Konverter Flyback.}

Pengujian dilakukan untuk mengetahui bentuk gelombang pada komponen induktor $\mathrm{Lr}$ dan kapasitor $\mathrm{Cr}$ pada rangkaian ZCS konverter flyback sebagai ozonisasi. Bentuk gelombang tersebut digunakan untuk mengetahui proses pensaklaran pada mode ZCS dengan menggunakan osiloskop. Gambar 4 merupakan skema rangkaian pengujian mode pensaklaran ZCS.

Gambar 5 memperlihatkan bentuk gelombang arus induktor $\mathrm{L}_{\mathrm{r}}$ (berwarna biru tua) dan gelombang pemicuan rangkaian kontrol (berwarna merah). Gelombang pemicuan rangkaian kontrol digunakan sebagai acuan pensaklaran MOSFET pada saat kondisi $O F F$ atau $O N$. Dapat diamati saat kondisi slope $O N$ pada MOSFET, arus pada induktor $\mathrm{L}_{\mathrm{r}}$ akan mengalami kenaikan karena terjadi pengisian arus (charging) pada induktor $\mathrm{L}_{\mathrm{r}}$. Kemudian saat kondisi $O N$ pada MOSFET arus pada induktor $\mathrm{L}_{\mathrm{r}}$ akan mengalami penurunan karena pada induktor $L_{r}$ mengalami pengosongan arus. Saat kondisi Turn ON pada MOSFET arus induktor $\mathrm{L}_{\mathrm{r}}$ bernilai nol, maka dapat dikatakan bahwa proses zero current switching terjadi pada saat pensaklaran MOSFET dalam kondisi Turn ON [15].

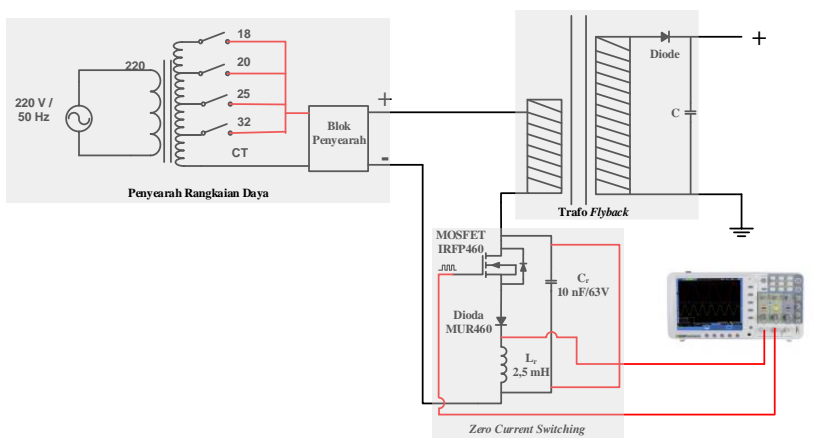

Gambar 4. Skema Rangkaian Pengujian Mode Pensaklaran ZCS

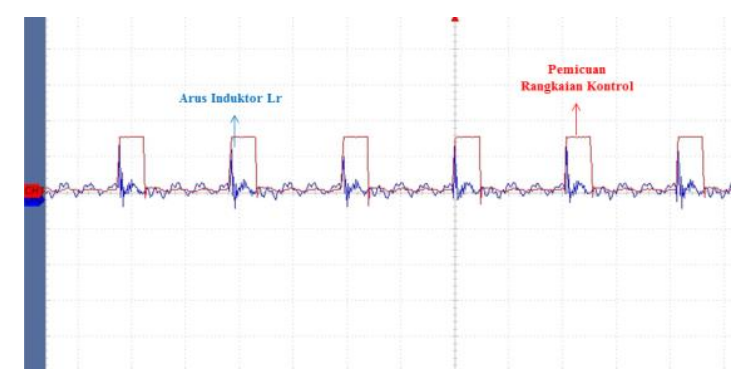

Gambar 5. Gelombang Arus Induktor $\left(L_{r}\right)$ dan Gelombang Pemicuan Rangkaian Kontrol
Gambar 6 meperlihatkan bentuk gelombang tegangan kapasitor $\mathrm{C}_{\mathrm{r}}$ (berwarna biru tua) dan gelombang pemicuan rangkaian kontrol (berwarna merah). Komponen kapasitor $\mathrm{C}_{\mathrm{r}}$ dirangkai paralel dengan komponen MOSFET, maka tegangan yang terdapat pada komponen kapasitor $\mathrm{C}_{\mathrm{r}}$ merepresentasikan tegangan pada MOSFET sebagai komponen pensaklaran. Dari Gambar 6 dapat diamati tegangan pada kapasitor $\mathrm{C}_{\mathrm{r}}$ mengalami kenaikan pada saat MOSFET dalam kondisi $O F F$ dan bernilai nol pada saat MOSFET dalam kondisi $O N$. Hal ini dikarenakan pada saat MOSFET dalam kondisi $O N$ arus mengalir pada MOSFET tetapi tidak mengalir ke kapasitor $\mathrm{C}_{\mathrm{r}}$ karena nilai resistansi MOSFET lebih kecil. Pada saat MOSFET OFF terjadi pengisian tegangan pada kapasitor $\mathrm{C}_{\mathrm{r}}$ oleh kumparan primer trafo. Karena terjadi pembalikan polaritas di sepanjang kumparan primer trafo.

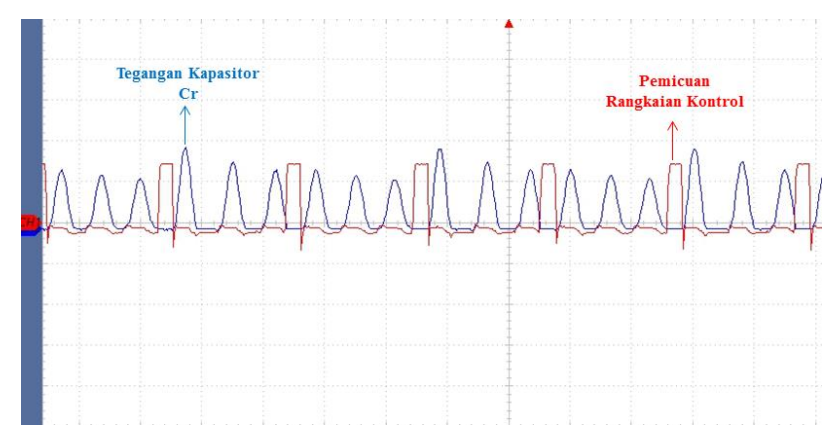

Gambar 6. Gelombang Tegangan Kapasitor $\left(C_{r}\right)$ dan Gelombang Pemicuan Rangkaian Kontrol

\subsection{Pengujian Tegangan Keluaran Zero Current Switching (ZCS) Konverter Flyback}

Pengujian tegangan keluaran ZCS konverter flyback akan diukur dengan mengatur nilai duty cycle dari rangkaian kontrol. Nilai frekuensi dari rangkaian kontrol yang digunakan adalah $23 \mathrm{kHz}$. Sedangkan untuk duty cycle yang digunakan dengan rentang 2,5 - $70 \%$. Pengukuran tegangan keluaran pada ZCS konverter flyback ini dilakukan tanpa beban atau tidak disambungkan terhadap reaktor ozon. Gambar 7 merupakan skema pengujian tegangan keluaran dari ZCS konverter flyback.

Gambar 8 menunjukkan gelombang keluaran tegangan ZCS konverter flyback dengan frekuensi switching $23 \mathrm{kHz}$. Gelombang tegangan keluaran ZCS konverter flyback ditunjukkan oleh gelombang berwarna biru tua (bawah) dan gelombang PWM ditunjukkan oleh gelombang berwarna merah (atas). Dapat diamati gelombang tegangan keluaran ZCS konverter flyback pada Gambar 10. merupakan gelombang tegangan tinggi impuls tertapis, karena pada komponen trafo flyback yang digunakan pada penelitian ini didalamnya terdapat komponen kapasitor[13]. Nilai tegangan yang dihasilkan oleh Gambar 8 dapat dihitung sebagai berikut. 


$$
\begin{aligned}
\text { Vout } & =\text { div vertikal } \times \text { volt } / \text { div } \times \text { pengali probe } \\
& =1,38 \text { div } \times 2 \mathrm{v} / \text { div } \times 1000 \\
& =2760 \mathrm{~V}
\end{aligned}
$$

Berdasarkan perhitungan dari Gambar 8. maka didapatkan nilai tegangan keluaran rangkaian ZCS konverter flyback adalah sebesar 2760 Volt.

Pada pengujian variasi Duty Cycle Terhadap Tegangan Keluaran ZCS Konverter Flyback dilakukan dengan 8 variasi nilai duty cycle yaitu : 2,5 \%, 10\%, 20\%, 30\% , $50 \%, 60 \%$ dan $70 \%$. Pada setiap variasi nilai duty cycle dilakukan pengukuran pada masing-masing tegangan masukan dari tapping trafo yaitu dengan nilai $15 \mathrm{~V}, 18 \mathrm{~V}$, $25 \mathrm{~V}$ dan $32 \mathrm{~V}\left(\mathrm{~V}_{\mathrm{AC}}\right)$. Pengukuran nilai tegangan keluaran dilakukan tanpa beban atau tidak terhubung reaktor ozon dan menggunakan bantuan dari osiloskop digital OWON. Hasil pengukuran tegangan keluaran ZCS konverter flyback variasi duty cycle ditunjukkan pada Tabel 1 .

Dari Tabel 1 dapat diketahui bahwa, pada rangkaian ZCS konverter flyback semakin tinggi nilai duty cycle yang digunakan maka nilai tegangan keluaran yang dihasilkan juga akan semakin tinggi. Atau dengan kata lain nilai duty cycle dan tegangan keluaran berbanding lurus.

Gambar 9. dapat memperlihatkan hubungan antara duty cycle dengan tegangan keluaran. Semakin tinggi nilai duty cycle maka nilai tegangan keluaran akan semakin tinggi. Variasi dari tegangan masukan memperlihatkan bahwa semakin tinggi nilai tegangan masukan dengan nilai duty cycle yang sama maka nilai tegangan keluaran yang dihasilkan semakin tinggi.

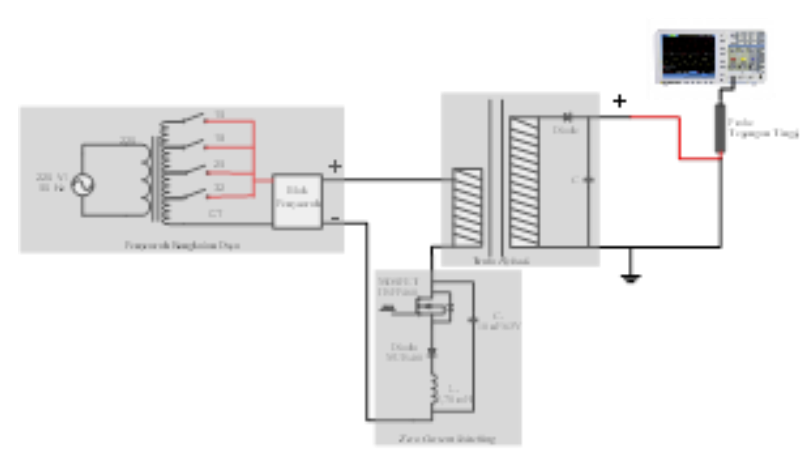

Gambar 7. Skema Pengujian ZCS Konverter Flyback

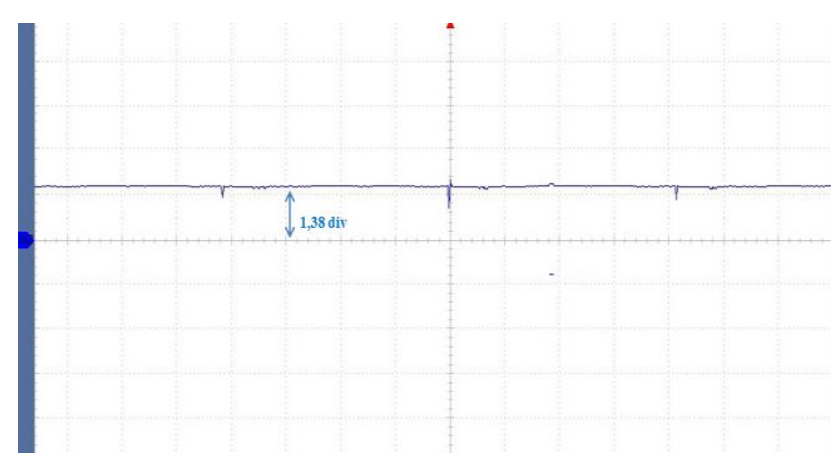

Gambar 8. Gelombang Tegangan Keluaran ZCS Konverter Flyback, f $_{\text {switching }}=23 \mathrm{kHz}$

Tabel 1. Data Tegangan Keluaran ZCS Konverter Flyback Variasi Duty Cycle (Dalam Satuan KV)

\begin{tabular}{ccccccccc}
\hline V input & \multicolumn{10}{c}{ Duty Cycle (\%) } \\
( $\mathrm{NAC})$ & $\mathbf{2 , 5}$ & $\mathbf{1 0}$ & $\mathbf{2 0}$ & $\mathbf{3 0}$ & $\mathbf{4 0}$ & $\mathbf{5 0}$ & $\mathbf{6 0}$ & $\mathbf{7 0}$ \\
\hline $15 \mathrm{~V}-\mathrm{CT}$ & 1,07 & 1,21 & 2,35 & 3,39 & 4,11 & 4,42 & 6,92 & 7,01 \\
$18 \mathrm{~V}-\mathrm{CT}$ & 1,31 & 1,46 & 2,75 & 4,85 & 5,12 & 5,42 & 7,19 & 7,65 \\
$25 \mathrm{~V}-\mathrm{CT}$ & 1,95 & 2,19 & 3,58 & 6,56 & 7,08 & 7,12 & 9,35 & 10,0 \\
$32 \mathrm{~V}-\mathrm{CT}$ & 2,40 & 2,81 & 3,92 & 6,91 & 7,60 & 7,93 & 10,7 & 11,0 \\
\hline
\end{tabular}

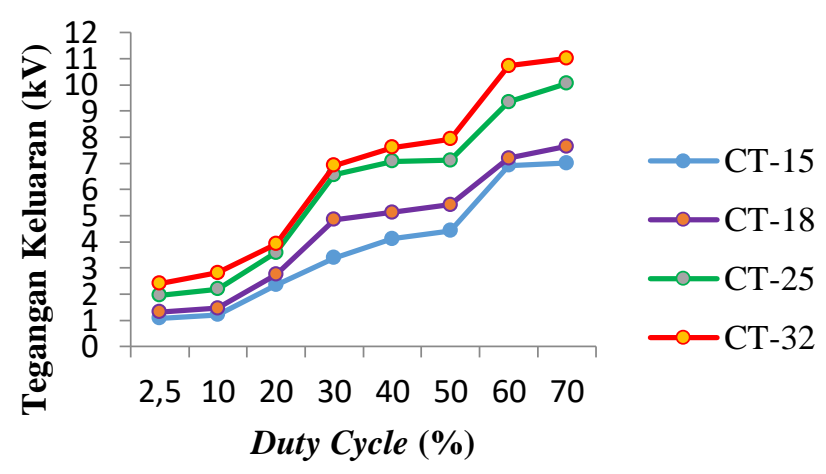

Gambar 9. Grafik Hubungan Duty Cycle dengan Tegangan Keluaran

\subsection{Pengujian Ozon}

Pada pengujian ozon ini dilakukan 5 variasi dari jarak antar elektroda, yaitu $9 \mathrm{~mm}, 7 \mathrm{~mm}, 5 \mathrm{~mm}, 3 \mathrm{~mm}$, dan $1 \mathrm{~mm}$. Gambar 10 merupakan skema pengujian pengukuran konsentrasi ozon dari reaktor ozon yang telah dibuat. 


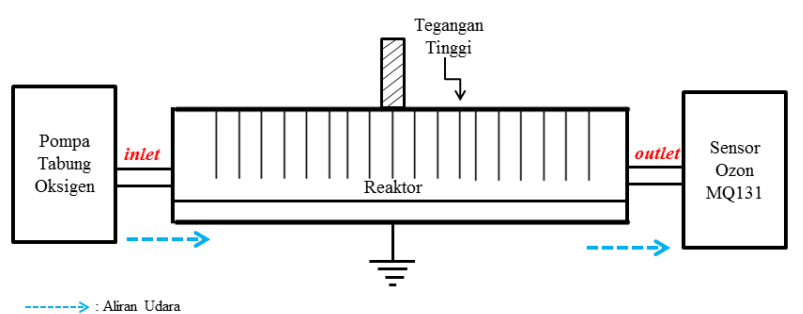

Gambar 10. Skema Pengujian Konsentrasi Ozon

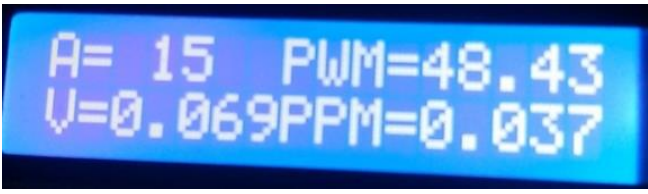

Gambar 11. Tampilan hasil dari Sensor Ozon MQ131

Tabel 2. Data Pengujian Ozon Variasi Jarak Elektroda dalam satuan ppm

\begin{tabular}{|c|c|c|c|c|c|}
\hline \multirow{2}{*}{ Vout (kV) } & \multicolumn{5}{|c|}{ Jarak Sela } \\
\hline & $9 \mathrm{~mm}$ & $7 \mathrm{~mm}$ & $5 \mathrm{~mm}$ & $3 \mathrm{~mm}$ & $1 \mathrm{~mm}$ \\
\hline 2,47 & 0 & 0 & 0 & 0 & Discharge \\
\hline 2,88 & 0 & 0 & 0,012 & 0,006 & Discharge \\
\hline 4,31 & 0 & 0 & 0,017 & Discharge & Discharge \\
\hline 6,36 & 0 & 0,017 & 0,017 & Discharge & Discharge \\
\hline 6,94 & 0,012 & 0,017 & 0,027 & Discharge & Discharge \\
\hline 7,04 & 0,022 & 0,022 & 0,032 & Discharge & Discharge \\
\hline 7,21 & 0,022 & 0,032 & 0,037 & Discharge & Discharge \\
\hline 7,47 & 0,032 & 0,037 & 0,066 & Discharge & Discharge \\
\hline
\end{tabular}

Dari Tabel 2. dapat diketahui bahwa, untuk tegangan keluaran ZCS konverter flyback pada variasi elektroda jarum diterapkan sebagai ground dan elektroda bidang diterapkan tegangan tinggi dengan nilai $2,47 \mathrm{kV} ; 2,88 \mathrm{kV}$; $4,31 \mathrm{kV}$; dan $6,36 \mathrm{kV}$ pada jarak elektroda $9 \mathrm{~mm}$ konsentrasi gas ozon yang dihasilkan bernilai 0 . Pada nilai 2,47 kV; 2,88 kV; dan 4,31 pada jarak sela $7 \mathrm{~mm}$ dan nilai $2,47 \mathrm{kV}$ pada jarak sela $5 \mathrm{~mm}$ dan $3 \mathrm{~mm}$ konsentrasi gas ozon yang dihasilkan juga bernilai 0 . Konsentrasi ozon tidak dapat dihasilkan karena medan listrik yang dihasilkan oleh elektroda pada jarak sela dan nilai tegangan tersebut belum cukup untuk mengubah oksigen dari tabung oksigen menjadi ozon. Kemudian untuk tegangan keluaran dengan jarak sela $9 \mathrm{~mm}$ rentang nilai $6,94 \mathrm{kV} ; 7,04 \mathrm{kV} ; 7,21 \mathrm{kV}$ dan $7,47 \mathrm{kV}$ nilai konsentrasi ozon yang dihasilkan berturut-turut 0,$012 ; 0,022 ; 0,022$; dan 0,032 (dalam satuan ppm).

Dari Tabel 2. juga dapat diketahui bahwa untuk tegangan keluaran ZCS konverter flyback pada variasi jarak $3 \mathrm{~mm}$ dengan nilai $2,88 \mathrm{kV} ; 4,31 \mathrm{kV} ; 6,36 \mathrm{kV} ; 6,94 \mathrm{kV} ; 7,04 \mathrm{kV}$; $7,21 \mathrm{kV} ; 7,47 \mathrm{kV}$ dan variasi jarak $1 \mathrm{~mm}$ dengan nilai 2,47
$\mathrm{kV} ; 2,88 \mathrm{kV} ; 4,31 \mathrm{kV} ; 6,36 \mathrm{kV} ; 6,94 \mathrm{kV} ; 7,04 \mathrm{kV} ; 7,21 \mathrm{kV}$ dan 7,47 kV konsentrasi ozon yang dihasilkan bernilai 0 karena pada tegangan tersebut terjadi discharge di reaktor ozon yang digunakan. Discharge sudah terjadi pada tegangan dengan nilai $4,31 \mathrm{kV}$ pada jarak sela $3 \mathrm{~mm}$ dan 2,47 kV pada jarak sela $1 \mathrm{~mm}$ karena medan yang dihasilkan terlalu besar sehingga terjadi lompatan muatan. Kemudian pada Tabel 4.5 dapat diketahui bahwa semakin tinggi nilai tegangan yang diterapkan pada reaktor ozon maka semakin tinggi nilai konsentrasi ozon yang dapat dihasilkan karena medan listrik yang dihasilkan diantara elektroda semakin besar. Perubahan jarak sela mempengaruhikonsentrasi ozon yang dihasilkan. Dengan tegangan yang sama, semakin kecil jarak sela yang digunakan maka nilai konsentrasi ozon yang dihasilkan semakin tinggi.

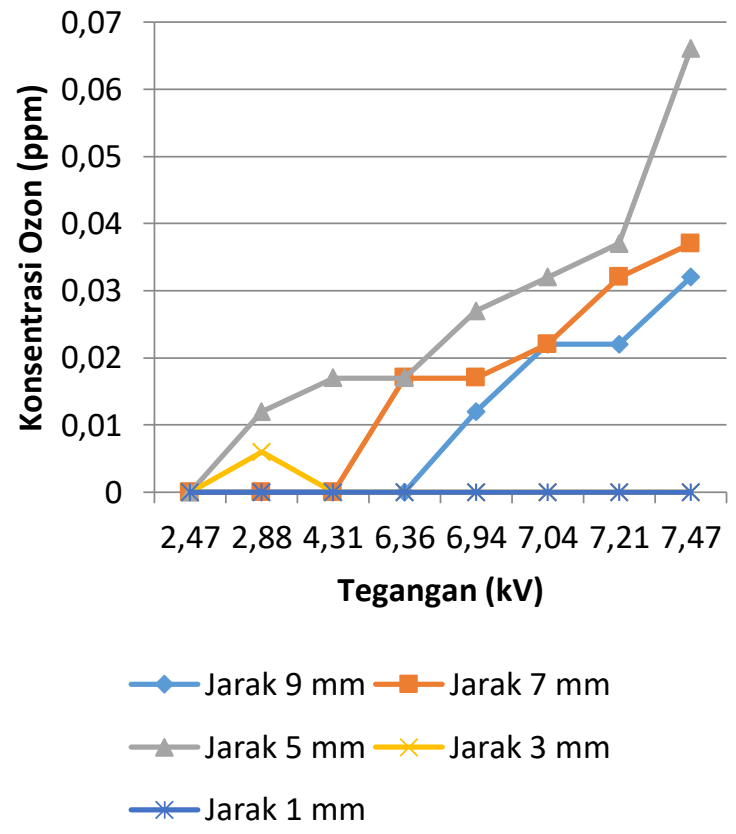

Gambar 12. Grafik Hubungan Tegangan Masukan (kV) dengan Konsentrasi Ozon (ppm)

Gambar 12. dapat memperlihatkan hubungan antara konsentrasi ozon dan jarak sela elektroda. Semakin tinggi nilai tegangan yang diterapakan pada reaktor ozon maka semakin tinggi nilai konsentrasi ozon yang akan dihasilkan [16]. Semakin dekat jarak sela elektroda maka semakin tinggi pula nilai konsentrasi ozon yang dihasilkan. Namun apabila jarak sela elektroda terlalu dekat, maka akan terjadi discharge pada reaktor ozon. Dari reaktor ozon dan tegangan keluaran ZCS konverter flyback yang digunakan, nilai konsentrasi ozon minimum dengan nilai 0,012 dihasilkan dari tegangan $6,94 \mathrm{kV}$ pada jarak $9 \mathrm{~mm}$ dan tegangan 2,88 kV pada jarak $5 \mathrm{~mm}$. Kemudian untuk nilai konsentrasi ozon maksimum dengan nilai 0,06 dihasilkan dari tegangan keluaran 7,47 kV dari jarak sela 5 milimeter. Dengan kata lain reaktor ozon dan tegangan keluaran ZCS 
konverter flyback pada penelitian ini dapat menghasilkan ozon pada rentang konsentrasi ozon dengan rentan 0,012 sampai dengan 0,066 ppm dengan variasi jarak sela elektroda yang bervariasi.

\section{Kesimpulan}

Pembangkit tegangan tinggi Zero Current Switching (ZCS) Konverter Flyback telah berhasil dibuat dan menghasilkan tegangan keluaran makskimal tanpa beban sebesar 11,01 $\mathrm{kV}$ dengan tegangan masukan $32 \mathrm{~V}_{\mathrm{AC}}$ pada duty cycle 70 $\%$. ZCS konverter flyback yang elah dibuat mampu melakukan pensaklaran dengan arus bernilai nol ketika MOSFET dalam kondisi Turn ON. Pada pengujian tegangan keluaran ZCS konverter flyback dengan variasi duty cycle dihasilkan tegangan keluaran tertinggi sebesar $11,01 \mathrm{kV}$ pada duty cycle $70 \%$. Semakin besar duty cycle yang diterapkan, maka tegangan keluarannya semakin tinggi. Pada pengujian ozon variasi jarak sela dihasilkan konsentrasi ozon tertinggi sebesar $0,066 \mathrm{ppm}$ pada jarak 5 mm dengan tegangan terapan $7,47 \mathrm{kV}$. Semakin tinggi tegangan yang diterapkan, maka konsentrasi ozon yang dihasilkan semakin banyak. Semakin dekat jarak sela elektroda maka semakin tinggi pula nilai konsentrasi ozon yang dihasilkan. Namun apabila jarak sela elektroda terlalu dekat, maka akan terjadi discharge pada reaktor ozon dan tidak ada ozon yang terdeteksi .

\section{Referensi}

[1]. B. L. Tobing, Dasar-Dasar Teknik Pengujian Tegangan Tinggi, Edisi Kedu. Jakarta: Lemeda Simarmata, 2012.

[2]. A. Arismunandar, Teknik Tegangan Tinggi. Jakarta Timur: Balai Aksara, 1983.

[3]. J. . A. Prakosa, M. Facta, and M. A. Riyadi, "Perancangan Pembangkit Tegangan Tinggi Impuls Berbasis Knverter Flyback," pp. 1-7, 2015.

[4]. A. S. Pandu, M. Facta, and A. Syakur, "Pembuatan Alat Pereduksi Gas CO pada Asap Rokok berbasis Cuk-Flyback Tegangan Tinggi," TRANSIENT, vol. 4, pp. 1-9, 2015.
[5]. I. L. Purba, M. Facta, and A. Syakur, "Perancangan Pembangkit Tegangan Tinggi Impuls Untuk Mengurangi Jumlah Bakteri Pada Cairan Susu Perah," TRANSIENT, vol. 2, 2013.

[6]. A. Mahmud, A.Syakur, and M. A. Riyadi, "Perancangan Pembangkit Tegangan Tinggi Impuls $12,80 \mathrm{kV}$ dengan Menerapkan Zero Current Switching (ZCS) pada Konverter Flyback," pp. 17, 2017.

[7]. F. Arifin, A. Warsito, and A. Syakur, "Perancangan Pembangkit Tegangan Tinggi Impuls Untuk Aplikasi Pengolahan Limbah Cair Industri Minuman Ringan Dengan Teknologi Plasma Lucutan Korona," TRANSIENT, pp. 1-7, 2011.

[8]. Bimo, A. Syakur, and A. Warsito, "Aplikasi Ignition Coil Sebagai Pembangkit Tegangan TInggi Impuls Untuk Penyedia Daya Reaktor Ozon," TRANSIENT, pp. 82-97. 2005

[9]. B. Yusuf, A. Warsito, A. Syakur, I. N. Widiasa, and J. P. Soedharto, "Aplikasi pembangkit tegangan tinggi impuls Untuk Pembuatan Reaktor Ozon," TRANSIENT, pp. 1-6, 2009.

[10]. H. Nirmala, A. Warsito, and M. Facta, "Penggunaan Zero Current Switching Buck Konverter Untuk Pengisi Akumulator," TRANSIENT, pp. 82-97. 2016

[11]. M. K. Kazimierczuk, Pulse-width Modulated DCDC Power Converters. 2008.

[12]. V. Siliconix, "Power MOSFET," no. V, pp. 1-9, 2008.

[13]. M. Flyback Transformers, "Flyback Transformers," p. 1, 201AD.

[14]. D. INCORPORATED, "DIODE MUR460," pp. 12.

[15]. M. Amjad, Z. Salam, M. Facta, and K. Ishaque, "Design and Development of a High-Voltage Transformer-less Power Supply for Ozone Generators Based on a Voltage-fed Full Bridge Resonant Inverter,'J. Power Electron., Vol. 12, no.3, pp. 387-398, 2012.

[16]. M. Facta, Z. Salami, and Z. Buntae, "Double Dielectric Barrier Discharge Chamber for Ozone Generation," no. 1, pp. 409-412, 2014. 